\title{
BOOK REVIEW \\ IDENTIFICATION GUIDE TO THE ANT GENERA \\ OF THE WORLD
}

\author{
BY BARRY BOLTON
}

1994

Harvard University Press

Cambridge, Massachusetts

A surge of interest in ants is sweeping through biology, due in no small part to the calculated efforts of B. Hölldobler and E.O. Wilson, whose seven-pound Pulitzer Prize-winning instant classic, The Ants (1990), provided more than enough critical mass to insure a sustained reaction. Chapter 2 of that work did its level best to supply the baseline knowledge necessary for comprehending ant morphological diversity, distribution, and classification, but fell short of the ideal of a self-contained key, atlas, and bench reference. Now, Barry Bolton of the British Museum, who authored some of the keys in that volume, has fulfilled this need by publishing the Identification Guide to the Ant Genera of the World.

Hölldobler and Wilson were the first in the history of myrmecology to assemble in one place representative illustrations, in the form of line drawings, of all extant ant genera. Bolton has taken this worthy goal to a sublime level by including scanning electron micrographs of both a full-face view and a body profile for the worker caste of nearly every described genus. These SEM's are for the most part clear and well executed, with the result that, for the first time ever, the full range of morphology in the family Formicidae may easily be perused and appreciated by any interested person, regardless of myrmecological background. The overall result is nothing less than an opulent visual atlas of genus-level ant diversity. Perhaps more importantly, the Identification Guide to Ant Genera of the World serves as a much-needed reference for: 1) current classification, 2) genus-level identification of the world fauna, 3) external ant-specific morphology, and 4) the systematic literature relevant at the genus level and above.

Manuscript received 17 November 1994. 
The higher classification of the ants has changed dramatically even in the short time since the publication of Hölldobler and Wilson's book, and intervening developments are reflected in Bolton's volume. Most importantly, a recent family-spanning cladistic analysis (Baroni-Urbani et al., 1992) has resulted in the division of the Formicidae into sixteen extant subfamilies rather than the eleven recognized in Hölldobler and Wilson. All sixteen appear in two subfamily-level keys in Bolton's first chapter (one key utilizing certain phylogenetically important internal characters of the exoskeleton), and each receives a subsequent chapter-length treatment. These subfamily chapters include a lengthy diagnosis of the defining characters of the worker, keys to genera (divided, as in Hölldobler and Wilson, into major zoogeographic areas), a synoptic classification, notes on geographic distribution, taxonomic references, and, or course, the SEM's.

In his synoptic classifications of the subfamilies, Bolton provides useful lists of synonomies of both tribe and genus names. He also goes farther than any previous worker in attempting to define tribal-level groupings, in some cases departing radically from prior schemes (e.g., Wheeler and Wheeler, 1985; Hölldobler and Wilson, 1990). This could be regarded by some investigators as a fault. However, to the extent that these groupings reflect Bolton's considerable knowledge of the ants, these synopses may alternately be interpreted as informed hypotheses of relationship that are open to further test, and thus as an advance over existing schemes that require islands of single-genus tribes or dangling genera with no tribal affiliations at all. Ultimately, however, Bolton makes no attempt to present information below the subfamily level in a phylogenetic framework, and, given the current state of affairs in ant systematics, such an attempt would clearly be premature.

Bolton's keys are a substantial improvement on those that appear in Hölldobler and Wilson. The keys presented in the latter volume, although a revolutionary advance over anything existing previously, nonetheless suffer from a number of vexing problems. Chief among these is the lack of any supporting illustrations, i.e., the keys never refer the reader to figures illustrating the verbally described features. A second problem is that numerous terms are used but never defined. Attempts to solve this by using the Hölldobler and Wilson keys in tandem with a copy of the venerable 
Torre-Bueno Glossary of Entomological Terms (1989) are largely futile: many ant-specific terms are also absent from that work. A third problem is that the keys appear as a chapter in a volume that could not be more unwieldy as a lab-bench reference tool.

The advantage of the addition of illustrations to Bolton's keys, most of them clear SEM's of actual specimens, is easily demonstrated by a single example: The first couplet in the key to Neotropical Myrmicinae asks the reader to differentiate the presence of antennal scrobes below the eye (first lug, illustrated by twelve figures) from (second lug) cases of complete absence (twenty-four figures), scrobes above the eye (ten figures), scrobes anterior to the eye (three figures), or eyes and scrobes absent (four figures). In some cases the SEM's illustrate characters of the ants that, although important for classification, have until now only been described verbally or in drawings or (rarely) photographs; for example, the apical peg-like spines on the pygidium of the Cerapachyinae (Bolton's Figures 17 to 19), the helcium (Figures 58, 161 to 163), the presence/absence of a second metatibial spur (Figures 511-513), and the variation in number of teeth on the pretarsal claws of the hind leg (Figures 514-516).

The terms in Bolton's keys are painstakingly defined in a tenpage "Glossary of Morphological Terms," which surpasses all such previous references for the ants, including the equivalent two-page "Body Parts and Special Terms" subsection of Hölldobler and Wilson's Table 2-5 (pp. 31-32). For instance, the very important antispecific term "peduncle" is repeatedly used in the Hölldobler and Wilson key, but never defined or figured. In Bolton's glossary it receives a thorough eight-line definition ("The relatively narrow anterior section of the petiole ..."), with reference to two figures. (Interestingly, Bolton's definition partly disagrees with the one given for ants in the Torre-Bueno Glossary of Entomology [1989], presenting a minor problem in myrmecological etymology.) Another important term, "frontal carina," is likewise used extensively in Hölldobler and Wilson's keys and likewise never defined (although it is labeled in their Figure 2-2); it is briefly defined (four lines) in Torre-Bueno. Bolton gives it fifteen lines and four illustrations. Other important terms that are well defined in Bolton's book, but that do not appear in Hölldobler and Wilson or Torre-Bueno, or else are improperly defined for ants in the latter 
reference, include "guard setae," "torulus," endophragmal pit," and "promesonotal suture."

Even for common terms that appear in other glossaries, Bolton's definitions are characteristically more complete in detailing the range of character states present in the ants. For example, his discussion of "mandibles" occupies half a page. As we might expect from an author at the cutting edge of ant systematic research, recently discovered anatomical characters with important implications for ant phylogeny occur throughout the glossary, for instance "helcium" and "metasternal process."

One caveat: the glossary is intended for the specific purpose of defining terms that appear in Bolton's keys. This means that features useful for identification of workers below the genus level do not appear, including the terminologies of integumental sculpture and setal form. Many of these appear in Hölldobler and Wilson's Table 2-5, while the majority can be found in Torre-Bueno. Thus, the complete ant morphological library requires all three volumes. Also, the glossary is not perfect. Occasional terms that appear in the keys are not defined, e.g., "superocular carina," perhaps because they are composites of easily understood words.

The Identification Guide to the Ant Genera of the World summarizes modern ant systematics, and most criticisms that can be made of this work reflect the imperfect state of affairs in this branch of biological science. Chief among these criticisms is that the classifications used by Bolton will undoubtedly change as new data are gathered and analyzed. For instance, there are already signs that not all is well at the subfamily level, especially with the monophyly of the Ponerinae (Ward, 1994). A second criticism is that not all genera are included in the figures. By my count, of the 299 extant ant genera recognized by Bolton, 46 were not included, not counting those that are workerless or for which workers are unknown. In the majority of cases this is clearly again the result of an imperfection in ant systematics, namely the extreme rarity of specimens representing, e.g., the monotypic genera Santschiella, Pilotrochus, and Dacatria, which are known only from type specimens. In other cases, SEM's of genera are absent due to the likelihood of synonomy with another genus that was figured (e.g., Acanthomyops, which is probably a synonym for Lasius). Other 
exclusions are more perplexing (e.g., the attine genera $M y$ cetarotes, Mycetophylax, and Mycetosoritis), but at any rate are minimal.

Another minor criticism is that, although subfamily-level geographic distribution data are given in the form of numbers of genera occupying major zoogeographic regions, it is not easy to determine the province of a particular genus. In fact, the only way to accomplish this using Bolton's book is to scan each of the region-specific keys to determine whether the genus appears there. Fortunately, this information can be easily read from Hölldobler and Wilson's Table 2-2, another reason why the compleat myrmecologist must own both works.

Bolton's book represents a monumental step forward for myrmecology. Together with Hölldobler and Wilson's The Ants (1990) and, to a lesser extent, with Hölldobler and Wilson's Journey to the Ants (1994), this work virtually assures that the surge of biological interest in ants will continue to grow and that ants will increasingly come to be used as model organisms for a wide variety of questions. The simple reason for this is that the Identification Guide makes it easy for biologists with a minimal requisite of entomological background to identify for themselves ants to the level of genus, a virtue sufficient to facilitate new work on these insects. The Identification Guide also represents a major advance for those of us interested in ant phylogeny, since it makes explicit the character systems that are informative at the level of subfamily, proposes tribal-level hypotheses of relationship, and accurately summarizes current ant classification.

But even if all of these features are ignored, I can unhesitatingly recommend the Identification Guide to the Ant Genera of the World to the broadest possible general audience simply for the pictures. E.O. Wilson once commented that "If human beings were not so impressed by size alone, they would consider an ant more wonderful than a rhinoceros." The SEM's in this book are the closest we can hope to come to removing this size prejudice, and virtually anyone with even a mild interest in biology could spend a few fascinated hours leafing through its pages and marveling that "mere ants" are actually some of the most baroque and strangely beautiful creatures on planet Earth. 


\section{REFERENCES}

Baroni Urbani, C., B. Bolton, and P.S. Ward. 1992. The internal phylogeny of ants (Hymenoptera: Formicidae). Systematic Entomology 17:301-329.

Hölldobler and Wilson. 1990. The Ants. Cambridge, Massachusetts: Harvard University Press.

Hölldobler and Wilson. 1994. Journey to the Ants: A Story of Scientific Exploration. Cambridge, Massachusetts: Harvard University Press.

Ward, P.S. 1994. Adetomyrma, and enigmatic new ant genus from Madagascar (Hymenoptera: Formicidae), and its implications for any phylogeny. Systematic Entomology 19:159-175.

Torre-Bueno, J.R. de la. 1989. The Torre-Bueno Glossary of Entomology. Revised edition, compiled by S.W. Nichols. New York: New York Entomological Society.

Wheeler, G.C. and J. Wheeler. 1985. A simplified conspectus of the Formicidae. Transactions of the American Entomological.Society 111:255-264.

By Ted R. Schultz; Dept. of Entomology, Comstock Hall, Ithaca, New York 14853-0901. 

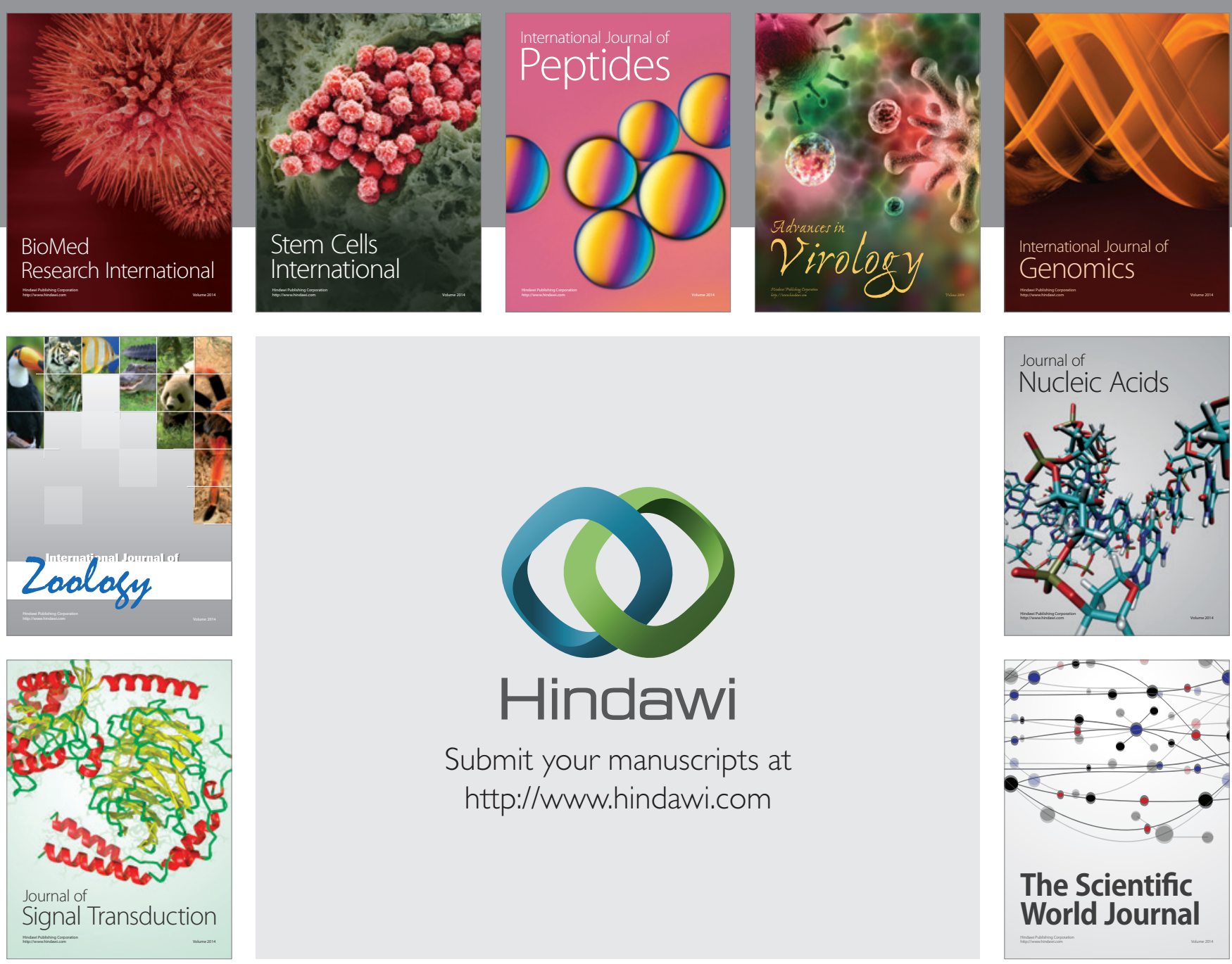

Submit your manuscripts at

http://www.hindawi.com
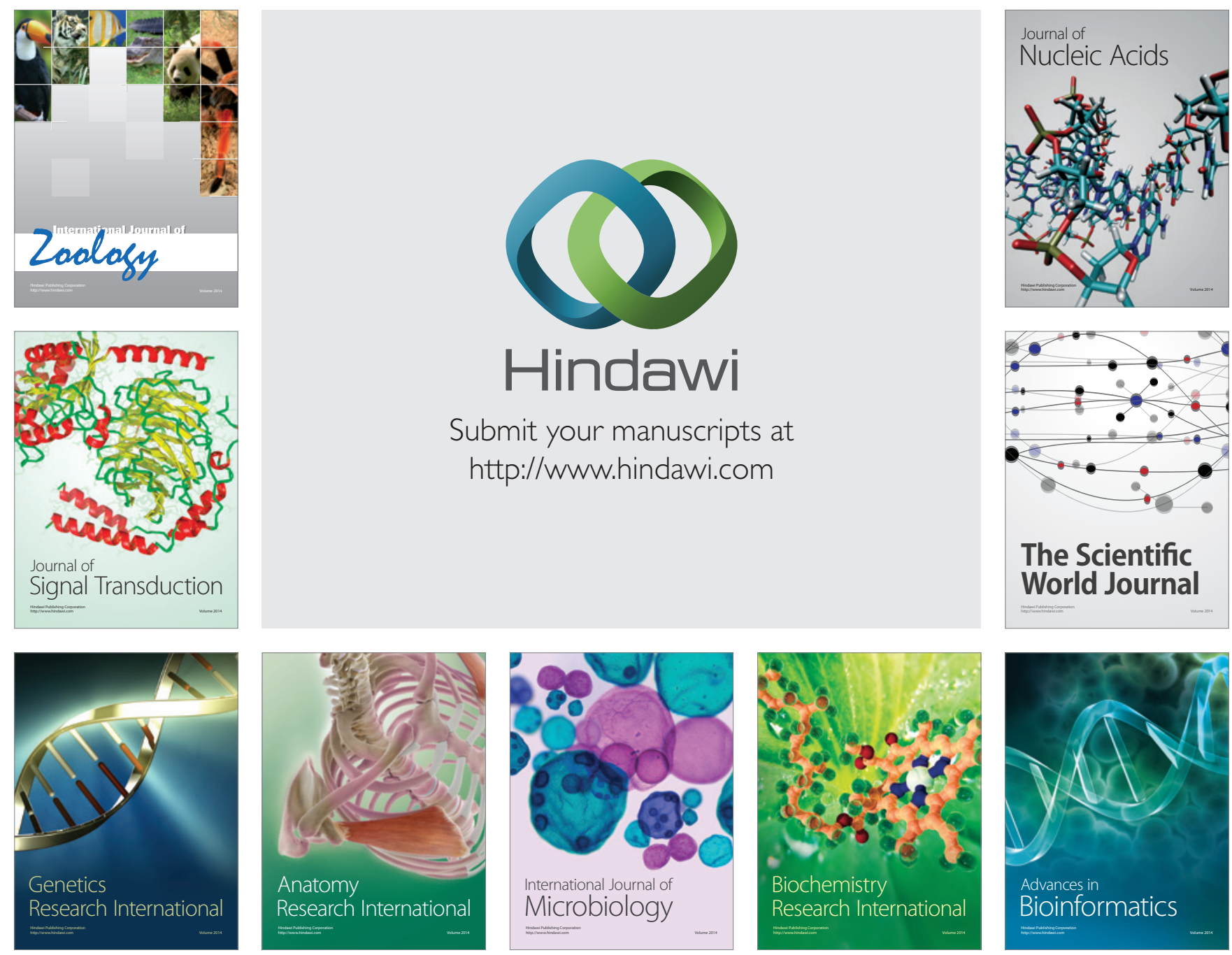

The Scientific World Journal
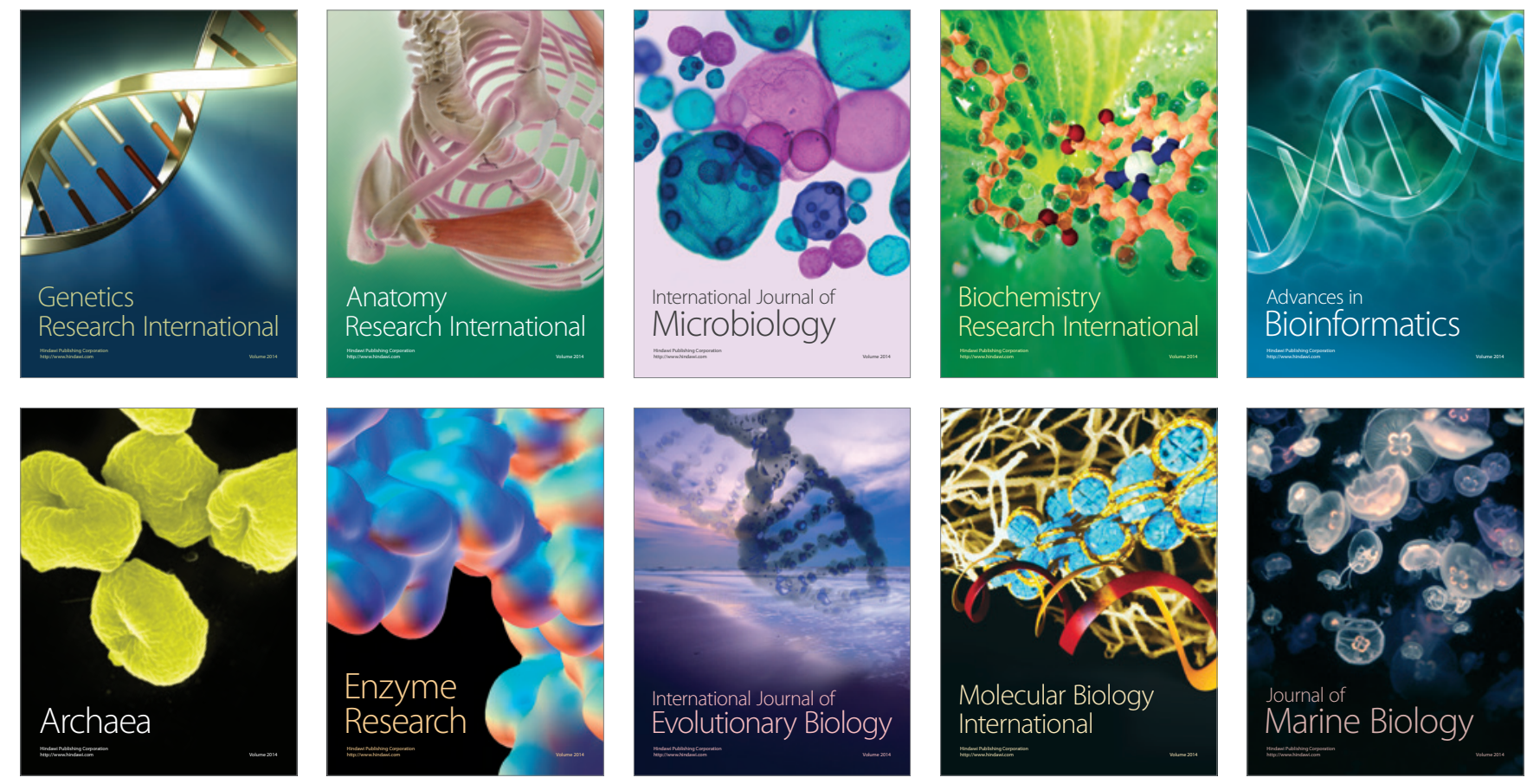